\title{
The occurrence, management and outcomes of post partum haemorrhage in a teaching hospital in Sri Lanka
}

\author{
Malik Goonewardene ${ }^{1}$, Chamari de Silva ${ }^{2}$, Madusha Medawala ${ }^{2}$, Sumali Karunarathna ${ }^{2}$ \\ Sri Lanka Journal of Obstetrics and Gynaecology 2012; 34: 144-154
}

\begin{abstract}
Introduction: In Sri Lanka post partum haemorrhage $(\mathrm{PPH})$ accounted for $12.7 \%$ of maternal deaths in 2008. In 2009 The Sri Lanka College of Obstetricians and Gynaecologists carried out an in-service training program to reduce maternal morbidity and mortality from PPH.
\end{abstract}

Objective: To evaluate the occurrence, management and outcomes of PPH in a teaching hospital in Sri Lanka and to identify appropriate remedial measures to improve the outcome of PPH.

Design, Setting and Methods: Criteria based input, process and outcome indicators were used to carry out a clinical audit at the Academic Unit of the Teaching Hospital, Mahamodara Galle from 01 June 2010 to 31 December 2011. Areas where appropriate remedial measures could be adopted to prevent $\mathrm{PPH}$ and also improve its outcome were identified.

Results: Of the 61 cases of PPH, 97\% were identified by the need for blood or colloid transfusion. Morbidity and severe morbidity due to $\mathrm{PPH}$ and severe PPH were approx. 130 times and 50 times more respectively, compared to the deaths from $\mathrm{PPH}$ in 2008. PPH following Caesarean section (CS) and instrumental vaginal delivery (IVD) were approx. 1.3 times and 3.5 times higher compared to $\mathrm{PPH}$ after normal vaginal delivery. Induction of labour (IOL) or Augmentation of labour (AOL) were the two leading risk factors identified. Genital tract trauma was an underlying cause in 59\% of cases. Suboptimal management processes identified included: delayed shifting to the operating theatre, delayed involvement of a specialist, not checking haematological status of the patient prior to discharge from hospital, and poor documentation.

\footnotetext{
${ }^{1}$ Senior Professor and Head

${ }^{2}$ Demonstrators, Academic Department of Obstetrics and Gynaecology, Teaching Hospital, Mahamodara Galle, Sri Lanka.

Correspondence: Malik Goonewardene

E-mail:malikg@eureka.lk
}

Conclusions: Morbidity due to PPH is far greater than mortality. IVD and CS should be carried out only when indicated and in properly selected cases. Measures should be adopted to prevent or reduce genital tract trauma. Women with IOL and AOL need close monitoring after delivery. The suboptimal management processes indentified should be corrected.

Key words: Postpartum haemorrhage, criteria based clinical audit

\section{Introduction}

Primary post partum haemorrhage (PPH), defined as a loss of $500 \mathrm{ml}$ or more of blood within the first 24 hours after childbirth, remains as an important cause of maternal morbidity and mortality worldwide ${ }^{1,2}$. Obstetric haemorrhage is estimated to occur in approximately $30.8 \%$ (95\% CI $5.9-48.5 \%$ ) of maternal deaths and is the leading cause of maternal mortality in $\mathrm{Asia}^{3}$. In 2004, the International Confederation of Midwives (ICM) and the International Federation of Gynaecology and Obstetrics (FIGO) launched an initiative to improve the prevention and treatment of $\mathrm{PPH}^{4}$. All professional associations were invited to join this ICM/FIGO initiative. In 2009, the Sri Lanka College of Obstetricians and Gynaecologists (SLCOG) joined this initiative.

Sri Lanka has successfully reduced maternal mortality from approximately 2000 per 100,000 live births in 1930 to 33.4 per 100,000 live births in 2008 . Although the rate of decline was dramatic between 1930 and 1970, it is less marked thereafter. PPH remains as the leading cause and accounted for $12.7 \%$ of maternal deaths (approx. 4.3 per 100,000 live births) in $2008^{5}$. This is in spite of approximately $99 \%$ of women having hospital deliveries with a skilled birth attendant at delivery ${ }^{6}$, and the routine practice of the recommended active management of the third stage of labour ${ }^{7}$.

Studying only the mortality due to PPH is misleading as deaths constitute only the tip of the much larger iceberg of morbidity. Therefore the study of severe acute maternal morbidity and near miss cases is important ${ }^{8,9}$. Criteria based clinical audits using this 
concept, have been suggested as being effective tools in improving the management and the quality of care and thus leading to reductions of maternal morbidity and mortality in general as well as in $\mathrm{PPH}^{8-11}$.

The SLCOG developed a training program on the prediction, prevention, early diagnosis and management of $\mathrm{PPH}$, for all intra partum care givers. This training program which is based on international and national guidelines ${ }^{12-16}$, has been conducted from 2009 in several districts which have relatively higher maternal mortality ratios compared to the other districts in Sri Lanka. The training program includes a lecture discussion, video presentations, a PPH drill and hands-on training stations on: visual estimation of blood loss, management of retained placenta with intra umbilical vein oxytocin injection or manual removal of placenta, bimanual uterine compression, condom catheter uterine tamponade, repair of genital tract injuries, uterine compression sutures, systematic uterine devascularization and internal iliac artery ligation. The training program was conducted at the Teaching Hospital, Mahamodara, Galle (THMG) Sri Lanka in March 2009. The objectives of this training programme were to reduce the case fatality rate and severe morbidity due to $\mathrm{PPH}$, and to improve prevention, early detection and appropriate management of PPH. The outcome of this training programme needs to be measured by detailed input, process and outcome indicators, and indicators used to monitor quality of obstetric care in the management of PPH.

Therefore a criteria based clinical audit on the prevention, early detection and appropriate management of PPH was designed and carried out in the THMG Sri Lanka, based on the SLCOG Guidelines and the Training Program. At the end of this audit, it is expected that areas for improvement would be identified and appropriate measures could be taken to train/re-train all intrapartum care givers in the areas which need such interventions.

\section{Method}

Standards were developed for the prevention and management of $\mathrm{PPH}$, based on international and national guidelines ${ }^{12-16}$. Indicators were developed for monitoring and evaluating the outcome of $\mathrm{PPH} 8,9,17,18$. Using these standards and the indicators a criteria based audit was conducted at the THMG Sri Lanka during the period 1st June 2010 to 31st December 2011, to evaluate the current status in the occurrence and management of PPH and to measure its outcomes. Ethical approval was obtained from the Ethical Review Committee of the Faculty of Medicine, University of Ruhuna.

\section{Inclusion criteria for maternal morbidity and mortality from $\mathrm{PPH}$}

All woman presenting with any of the following conditions after child birth were included.

1. Uterine rupture or inversion.

2. Retained placenta.

3. Clinical interventions:

Use of blood products or colloids.

Condom catheter insertion for uterine tamponade.

Examination in operation theatre (OT) after vaginal delivery.

Return to OT after operative delivery.

Laparotomy (Includes hysterectomy, excludes caesarean section [CS]).

Admission to intensive care unit (ICU).

4. Maternal death.

\section{Additional criteria used to assess the management process}

- Whether risk factors for PPH were present and if so whether they were identified and appropriate preventive measures adopted

- The number of cases of retained placentae and the proportion successfully managed with intra umbilical vein oxytocin injection

- Timing of the detection of PPH, commencement of blood transfusion, involvement of a specialist and the decision for surgical intervention

- Repair of genital tract trauma

- Type of surgical intervention

- In the women who have an estimated blood loss of $>500 \mathrm{ml}$, the volume of crystalloids, colloids and blood transfused, and the haemoglobin levels prior to discharge from hospital and six weeks later

- Any woman who had any of the following criteria was considered to have had a severe $\mathrm{PPH}^{8,9}$.

Required five or more units of blood transfusion

Required surgical intervention in the OT

Required a post partum hysterectomy

Uterine rupture or inversion

Admission to ICU 
The data were stored confidentially in an ongoing computer software database and analyzed using the computer software SPSS 11 (SPSS Inc. Chicago, Illinois, USA). The means with $95 \%$ confidence intervals, and the median with the interquartile range were used to describe parametrically and non-parametrically distributed continuous variables respectively. Proportions were used to describe categorical data. The Chi Square test was used to compare proportions and $p<0.05$ was considered as the level of significance.

\section{Definition of indicators to monitor quality of obstetric Care in the management of PPH}

(Adapted from the WHO Maternal Near Miss Audit ${ }^{9}$ )

- Severe maternal morbidity (SMM) from PPH refers to a woman who nearly died but survived a haemorrhage that occurred during childbirth or within 42 days of termination of pregnancy

- Maternal death (MD) is the death of a woman within 42 days of termination of pregnancy

- Live Birth (LB) refers to the complete expulsion or extraction from its mother of a product of conception, which, after such separation, breathes or shows any other evidence of life provided it is $>500 \mathrm{~g}$ and $>20 / 52$

- Women with life-threatening PPH (WLTPPH) refers to all women who either had a SMM from $\mathrm{PPH}$ or who died of PPH. It is the sum of SMM and MD.

[WLTPPH $=\mathrm{SMM}+\mathrm{MD}]$
- Severe maternal morbidity incidence ratio refers to the number of SMM cases per 1000 LB $[S M M$ IR = SMM /1000 LB]

- Severe maternal outcome ratio (SMOR) from $\mathrm{PPH}$ refers to the number of WLTPPH + MD due to PPH per 1000 LB. This indicator gives an estimation of the amount of care that would be needed in an area. $[\mathrm{SMOR}=(\mathrm{SMM}+\mathrm{MD})$ /LB]

- Severe maternal morbidity: Mortality ratio refers to the proportion between SMM cases and MD. Higher ratios indicate better care. [SMM: 1MD]

- Maternal mortality index of PPH refers to the number of MD divided by WLTPPH expressed as a percentage. The higher the index, more women with life threatening PPH die indicating low quality of care. The lower the index, fewer women with life-threatening $\mathrm{PPH}$ die indicating better quality of care. [MMI = MD/ $(\mathrm{SMM}+\mathrm{MD})]$

- Perinatal mortality rate, neonatal mortality rate and still birth rate are used to com-plement the quality of care evaluation

\section{Results}

During the period of study, 61 cases were included for the audit of PPH. The majority (52.5\%) were primigravidae between 27 to 31 years of age and only $4.9 \%$ were grande multigravidae Table 1.

Table 1. Patient characteristics $(n=61)$

\begin{tabular}{lcccccc}
\hline & & & & & \\
Mean Age in years & $(95 \% \mathrm{CI})$ & Range & $=$ & 29.2 & $(27.6-30.7)$ & $17-40$ \\
Median Parity & $(\mathrm{IQR})$ & Range & $=$ & 1 & $(2)$ & $1-7$ \\
Primigravidae & $(\%)$ & & $=$ & 32 & $(52.5 \%)$ & $(4.9 \%)$ \\
Parity $>4$ & $(\%)$ & Range & $=$ & 03 & $5-7$ \\
\hline
\end{tabular}

$95 \% \mathrm{CI}=95 \%$ Confidence Interval

$\mathrm{IQR}=$ Inter Quartile Range

Of the 61 cases 59 (98\%) were included because of the use of blood products or colloids. One patient managed with condom catheter tamponade without blood or colloid transfusion, and one patient managed with crystalloids and additional oxytocics were also included in the audit. Admission to ICU and examination in OT after vaginal delivery were additional criteria for inclusion of cases in $34 \%$ and $33 \%$ respectively. The proportions of cases having other inclusion criteria are described in Table 2. 
Table 2. Inclusion criteria $(n=61)$

\begin{tabular}{lcc}
\hline Criterion & $n$ & $\%$ \\
\hline Transfusion of blood or colloids & 59 & 96.7 \\
Admission to ICU due to PPH & 21 & 34.4 \\
Shifted to OT after vaginal delivery & 20 & 32.8 \\
Major surgical interventions (excluding CS) & 16 & 26.2 \\
Return to OT after CS & 3 & 4.9 \\
Use of condom catheter tamponade & 3 & 4.9 \\
Retained placenta & 3 & 4.9 \\
Uterine rupture & 1 & 1.6 \\
Use of oxytocin infusion and crystalloids & 1 & 1.6 \\
\hline ICU = Intensive care unit $\quad$ OT = Operation theatre & CS = Caesarean section
\end{tabular}

Out of 60 patients who were managed with blood products and colloids, only 57 had blood transfusions. Out of three patients who did not require blood transfusion, two were managed with colloids and one with crystalloids. Out of the 16 patients who underwent major surgical interventions excluding CS in the OT, six were after vaginal delivery and ten were after CS. There had been 96 women with retained placentae during this period and three of them had PPH (Table 2).

Table 3. Age and parity distribution and pattern of blood transfusions $(n=61)$

\begin{tabular}{|c|c|c|c|c|c|}
\hline & $P P H$ & $\begin{array}{c}\text { Mild PPH } \\
(<3 \text { blood units } \\
\text { transfused })\end{array}$ & $\begin{array}{c}\text { Moderate PPH } \\
\text { (3-4 blood units } \\
\text { transfused) }\end{array}$ & $\begin{array}{c}\text { Severe PPH } \\
(\geq 5 \text { blood units } \\
\text { transfused })\end{array}$ & $\begin{array}{l}\text { Blood not } \\
\text { transfused }\end{array}$ \\
\hline \multicolumn{6}{|l|}{ Age } \\
\hline$<20$ & 06 & 04 & 1 & 1 & 0 \\
\hline $20-29$ & 26 & 16 & 5 & 4 & 1 \\
\hline $30-39$ & 28 & 17 & 4 & 4 & 3 \\
\hline$>40$ & 01 & 0 & 0 & $1^{* *}$ & 0 \\
\hline \multicolumn{6}{|l|}{ Parity } \\
\hline $\mathrm{P}_{1}$ & 32 & 23 & 4 & 4 & 1 \\
\hline $\mathrm{P}_{2}-\mathrm{P}_{4}$ & 26 & 12 & 6 & 5 & 3 \\
\hline$>\mathrm{P}_{4}$ & 03 & 2 & 0 & $1^{* *}$ & 0 \\
\hline TOTAL & 61 & 37 & $10^{*}$ & $10^{*}$ & 4 \\
\hline
\end{tabular}

\footnotetext{
* Nine patients has 5-12 units.
}

** One patient who was 40 years old and a para 7, had 15 units of blood, 10 units FFP and 14 packs of platelets. 
Of the 57 patients who needed blood transfusion ten $(16 \%)$ needed more than five units. One patient who was 40 years old and a para 7 required 15 units of blood, 10 units of fresh frozen flasma (FFP) and 14 packs of platelets (Table 3). Due to severe haemorrhage three (5\%) patients were transfused uncrossmatched group specific blood as an emergency, 14 (22\%) were transfused with FFP and eight (13\%) were transfused with platelets. O Negative blood was not transfused.

Table 4. Mode of delivery and occurrence of post partum haemorrhage $(n=61)$

\begin{tabular}{|c|c|c|c|c|c|}
\hline & $n$ & PPH & Severe $P P H$ & $\begin{array}{l}\text { PPH per } \\
100,000 \\
\text { deliveries }\end{array}$ & $\begin{array}{c}\text { Severe PPH } \\
\text { per } 100,000 \\
\text { deliveries }\end{array}$ \\
\hline Normal vaginal deliveries & 6505 & 37 & 11 & 568.8 & 169.1 \\
\hline Caesarean section & 2846 & 21 & 11 & 737.9 & 386.5 \\
\hline - Intrapartum & & 09 & 04 & & \\
\hline - Antepartum & & 12 & 07 & & \\
\hline Instrumental deliveries & 151 & 03 & 01 & 1986.8 & 662.3 \\
\hline Total deliveries & 9502 & 61 & 23 & 642 & 242 \\
\hline
\end{tabular}

$\mathrm{PPH}=$ Post partum haemorrhage

Of the 61 cases $23(37 \%)$ were considered to be cases of severe PPH. Therefore the rate of PPH in the unit was 642 per 100,000 deliveries with severe PPH occurring in 242 per 100,000 deliveries. Occurrence of PPH in instrumental deliveries (662 per 100,000) was significantly higher than the occurrence of PPH in CS (387 per $100,000)$ and normal vaginal delivery $(169$ per 100,000$)(\mathrm{p}<0.001)($ Table 4$)$. There were no deaths due to PPH during this period. Therefore, WLTPPH $=23$ and SMMIR and SMOR $=2.4$ per 1000 live births. There were no perinatal deaths associated with $\mathrm{PPH}$ during this period.

Table 5. Risk factors for post partum haemorrhage $(n=61)$

\begin{tabular}{lll}
\hline Risk Factor & $n$ & $\%$ \\
\hline Augmentation of labour & 11 & 18 \\
Induction of labour & 10 & 16.4 \\
Hypertension in pregnancy & 6 & 9.8 \\
Placenta accreta & 4 & 6.6 \\
Prolonged stage I & 3 & 4.9 \\
Prolonged stage II & 3 & 4.9 \\
Macrosomia & 3 & 4.9 \\
Instrumental vaginal delivery & 3 & 4.9 \\
Grande multiparity & 3 & 4.9 \\
Placenta preavia & 2 & 3.3 \\
Multiple pregnancy & 2 & 3.3 \\
Retained products & 1 & 1.6 \\
Abruptio placentae & 1 & 1.6 \\
Anaemia & 1 & 1.6 \\
None & 24 & 39.3 \\
\hline
\end{tabular}


Induction of labour (IOL) or augmentation of labour (AOL) was associated with 21 (34\%) of cases of PPH. Hypertension in pregnancy and placenta accreta was associated with six (10\%) and four $(7 \%)$ of cases of $\mathrm{PPH}$ respectively. Prolonged stage I of labour, prolonged stage II of labour, macrosomia, instrumental vaginal delivery and grande multiparity were associated with three cases (5\%) of PPH each. Of the four cases with morbidly adherent placentae, three cases had one or more previous CS. No risk factors were found in 24 (39\%) of cases and 12 cases $(20 \%)$ had two risk factors while three (5\%) had three or more risk factors (Table 5).

Table 6. Diagnosis and management $(n=61)$

\begin{tabular}{|c|c|c|c|c|c|c|c|c|c|}
\hline & $\begin{array}{l}<15 \\
\min \end{array}$ & $\begin{array}{l}15-30 \\
\min \end{array}$ & $\begin{array}{c}30-60 \\
\min \end{array}$ & $\begin{array}{c}\text { 60-120 } \\
\text { min }\end{array}$ & $\begin{array}{l}>2 h r s \\
-<6 h r s\end{array}$ & $\begin{array}{l}>6 h r s- \\
<24 h r s\end{array}$ & $>24 h r s$ & $\begin{array}{l}\text { Not } \\
\text { recorded }\end{array}$ & $\begin{array}{c}\text { Not } \\
\text { Applicable }\end{array}$ \\
\hline $\begin{array}{l}\text { Timing of } \\
\text { diagnosis }\end{array}$ & $\begin{array}{c}18 \\
(29.5 \%)\end{array}$ & $\begin{array}{c}15 \\
(24.6 \%)\end{array}$ & $\begin{array}{c}11 \\
(18 \%)\end{array}$ & $\begin{array}{c}08 \\
(13.1 \%)\end{array}$ & $\begin{array}{c}06 \\
(9.8 \%)\end{array}$ & 0 & $\begin{array}{c}03 \\
(4.9 \%)\end{array}$ & 0 & 0 \\
\hline $\begin{array}{l}\text { Timing of } \\
\text { first blood } \\
\text { transfusion }\end{array}$ & $\begin{array}{c}03 \\
(4.9 \%)\end{array}$ & $\begin{array}{c}07 \\
(11.5 \%)\end{array}$ & $\begin{array}{c}11 \\
(18 \%)\end{array}$ & $\begin{array}{c}09 \\
(14.8 \%)\end{array}$ & $\begin{array}{c}08 \\
(13.1 \%)\end{array}$ & $\begin{array}{c}06 \\
(9.8 \%)\end{array}$ & $\begin{array}{c}13 \\
(21.3 \%)\end{array}$ & 0 & $\begin{array}{c}4 \\
(6.5 \%)\end{array}$ \\
\hline $\begin{array}{l}\text { Timing of } \\
\text { specialist } \\
\text { obstetrician } \\
\text { being inform }\end{array}$ & $\begin{array}{l}05 * \\
(8.2 \%)\end{array}$ & $\begin{array}{c}09 \\
(14.8 \%)\end{array}$ & $\begin{array}{c}11 \\
(18 \%)\end{array}$ & $\begin{array}{c}11 \\
(18 \%)\end{array}$ & $\begin{array}{c}06 \\
(9.8 \%)\end{array}$ & $\begin{array}{c}03 \\
(4.9 \%)\end{array}$ & $\begin{array}{c}02 \\
(3.3 \%)\end{array}$ & $\begin{array}{c}14 \\
(22.9 \%)\end{array}$ & 0 \\
\hline $\begin{array}{l}\text { Timing of } \\
\text { carrying out } \\
\text { condom catl } \\
\text { tamponade }\end{array}$ & 0 & 0 & 0 & $\begin{array}{c}01 \\
(1.6 \%)\end{array}$ & $\begin{array}{c}02 \\
(3.3 \%)\end{array}$ & 0 & 0 & 0 & $\begin{array}{c}58 \\
(95.1 \%)\end{array}$ \\
\hline
\end{tabular}

* In one case, the specialist carried out the caesarean section

Of the 61 cases of PPH 30\% and 55\% were detected within 15 minutes and 30 minutes respectively, and 5\% and $12 \%$ received blood transfusions with 15 minutes and 30 minutes respectively. A specialist was involved in the management within 30 minutes in $23 \%$ of cases but only after two hours in $18 \%$ of cases. In $23 \%$ of cases the timing of specialist involvement was not recorded (Table 6).

Table 7. Management in operation theatre after vaginal delivery $(n=20)$

\begin{tabular}{|c|c|c|c|c|c|c|c|c|c|}
\hline & $\begin{array}{l}<15 \\
\min \end{array}$ & $\begin{array}{l}15-30 \\
\min \end{array}$ & $\begin{array}{c}30-60 \\
\min \end{array}$ & $\begin{array}{l}\text { 60-120 } \\
\text { min }\end{array}$ & $\begin{array}{l}>2 h r s- \\
<6 h r s\end{array}$ & $\begin{array}{l}>6 h r s- \\
<24 h r s\end{array}$ & $>24 h r s$ & $\begin{array}{c}\text { Not } \\
\text { recorded }\end{array}$ & $\begin{array}{c}\text { Not } \\
\text { Applicable }\end{array}$ \\
\hline $\begin{array}{l}\text { Timing of } \\
\text { anaesthetist } \\
\text { being informe }\end{array}$ & d & $\begin{array}{c}03 \\
(15 \%)\end{array}$ & $\begin{array}{c}03 \\
(15 \%)\end{array}$ & $\begin{array}{c}06 \\
(30 \%)\end{array}$ & $\begin{array}{c}06 \\
(30 \%)\end{array}$ & $\begin{array}{c}01 \\
(5 \%)\end{array}$ & 0 & $\begin{array}{c}01 \\
(5 \%)\end{array}$ & 0 \\
\hline $\begin{array}{l}\text { Timing of } \\
\text { considering } \\
\text { shifting to OT }\end{array}$ & $\begin{array}{c}0 \\
(10 \%)\end{array}$ & $\begin{array}{c}02 \\
(15 \%)\end{array}$ & $\begin{array}{c}03 \\
(30 \%)\end{array}$ & $\begin{array}{c}06 \\
(30 \%)\end{array}$ & $\begin{array}{c}06 \\
(5 \%)\end{array}$ & $\begin{array}{c}01 \\
(10 \%)\end{array}$ & 0 & 02 & 0 \\
\hline $\begin{array}{l}\text { Timing } \\
\text { interval } \\
\text { decision to } \\
\text { commencemer } \\
\text { of surgery }\end{array}$ & $\begin{array}{l}01 \\
(5 \%) \\
\text { nt }\end{array}$ & $\begin{array}{c}02 \\
(10 \%)\end{array}$ & $\begin{array}{c}03 \\
(15 \%)\end{array}$ & 0 & 0 & 0 & 0 & 0 & $\begin{array}{c}0 \\
(70 \%)\end{array}$ \\
\hline
\end{tabular}


Of the 20 cases shifted to the OT after vaginal delivery, only five (25\%) were shifted to the OT within 60 minutes while seven (35\%) were shifted to the OT after 120 minutes (Table 7).

Table 8. Underlying cause of postpartum haemorrhage $(n=61)$

\begin{tabular}{llc}
\hline & Managed with medical treatment & 19 \\
Hypotonia $(\mathbf{n = 1 9 )}$ & Managed with condom catheter tamponade & 3 \\
& Managed surgically & 5 \\
& Perineal tears & 23 \\
Trauma $(\mathbf{n}=\mathbf{3 0})$ & Vaginal / Cervical tears & 1 \\
Retained tissue $(\mathbf{n}=\mathbf{6})$ & Placenta expelled + retained tissue & 1 \\
& Retained placenta & 4 \\
Hypotonia + trauma $(\mathbf{n}=\mathbf{5})$ & Placenta accreta & \\
Trauma + retained tissue $(\mathbf{n}=\mathbf{1})$ &
\end{tabular}

Of the 61 cases of PPH, hypotonia was present only in 24 (39\%) and trauma was an underlying cause in 36 (59\%). No risk factor was detected in 28 (13\%) of cases (Table 8$)$.

Table 9. Medical management of postpartum haemorrhage $(n=61)$

\begin{tabular}{lcc}
\hline & $n(\%)$ & Not documented \\
\hline $\begin{array}{l}\text { Active management of } \\
\text { IIIrd Stage of labour }\end{array}$ & $53(86.9)$ & 8 \\
$\begin{array}{l}\text { Therapeutic } \\
\text { oxytocin / ergometrine }\end{array}$ & $48(78.6)$ & 13 \\
Sulprostone & $13(21.3)$ & 48 \\
Tranexamic acid & $29(47.5)$ & 32 \\
\hline
\end{tabular}

The use of ergometrine or oxytocin for active management of third stage of labour was not documented in $13 \%$ of cases and their use as therapeutic measures was not documented in $21 \%$ of cases. Tranexamic acid and sulprostone were used in $47.5 \%$ and 21.3 of cases respectively (Table 9). 
Table 10. Use of oxytocics and intravenous fluids in the management of postpartum haemorrhage $(n=61)$

Total recorded dose of ergometrine-mg:

$\mathrm{n}=42$ Median (IQR), Range

$0.5-1.5$

Total recorded dose of oxytocin - IU: $n=41$

Mean $(95 \% \mathrm{CI})$, Range

$5-120$

Total recorded volume of crystalloids prior to

blood transfusion-ml: $\mathrm{n}=45$

Mean $(95 \% \mathrm{CI})$, Range

$1167.8 \quad(1035.7-1299.8) \quad 500-2500$

Total recorded volume of crystalloids-ml: $n=51$

Mean $(95 \% \mathrm{CI})$, Range

$1510.8 \quad(1337.4-1684.2) \quad 500-3500$

Total recorded volume of colloids prior to

blood transfusion-ml: $\mathrm{n}=26$

Mean (95\% CI), Range

692.3

$(537.8-846.8) \quad 500-2000$

Total recorded volume of colloids-ml: $\quad n=26$

Mean (95\% CI) , Range

769.2

$(579.1-959.3)$

$500-2000$

The recorded doses of ergometrine and oxytocin used and the recorded volumes of crystalloids and colloids transfused, is shown in Table 10. Of 61 subjects $26(45 \%)$ were given colloids prior to blood transfusion. The transfusion of crystolloids was not documented in 10 (16\%) of cases. (Table 10).

Table 11. Interventions for management of postpartum haemorrhage $(n=61)$

\begin{tabular}{lcc}
\hline Method & $n$ & $\%$ \\
\hline Vaginal packing & 29 & 47.5 \\
Condom catheter uterine tamponade & 3 & 4.9 \\
Intra-umbilical vein oxytocin injection for retained placenta & 3 & 4.9 \\
Manual removal of retained placenta & 3 & 4.9 \\
Post partum evacuation of retained products of conception & 1 & 1.6 \\
B Lynch / Compression sutures & 2 & 3.3 \\
Systematic devascularisation & 2 & 3.3 \\
$\begin{array}{l}\text { Post partum hysterectomies } \\
\text { (includes caesarean hysterectomies) }\end{array}$ & 13 & 21.3 \\
Bilateral internal iliac artery ligation & 5 & 34.4 \\
Admission to intensive care unit & 21 &
\end{tabular}

Vaginal packing was carried out in $48 \%$ of cases, a hysterectomy in $21 \%$ and bilateral internal iliac artery ligation in $8 \%$. ICU care was required in $34 \%$ of cases (Table 11 ). 
Table 12. Haemoglobin level and haematocrit $(n=61)$

$\begin{array}{ll}\begin{array}{l}\text { Pre-transfusion } \\ \text { haemoglobin checked }\end{array} & \mathrm{n}=40 \quad(65.6 \%) \\ \begin{array}{l}\text { Haemoglobin on } \\ \text { discharge: } \mathrm{n}=52\end{array} & 10.4 \quad(10.2-10.5) \\ \text { Mean (95\% CI) Range } & 8.8-13.4 \\ \begin{array}{l}\text { Haematocrit on } \\ \text { discharge: } \mathrm{n}=37\end{array} & 31.1(29.9-32.3) \\ \text { Mean }(95 \% \mathrm{CI}) \text { Range } & 21-40\end{array}$

The patient's haemoglobin was checked in 40 $(65.6 \%)$ of cases prior to blood transfusion and 52 $(85 \%)$ of cases prior to discharge from hospital (Table 12).

\section{Discussion}

The distribution of age and parity in the women who had PPH probably reflects the age and parity distribution of all the women who delivered in the unit during this period.

The requirement of a blood transfusion or colloid infusion within 24 hours after child birth is the easiest method of identifying cases of significant PPH after the event, and thereby quantifying the rate of $\mathrm{PPH}$. Severe PPH has been defined as loss of one blood volume within a 24 hour period or a loss of $50 \%$ blood volume within three hours or a rate of blood loss of $>150 \mathrm{ml}$ per minute ${ }^{19}$. A pregnant woman is thought to have approximately $100 \mathrm{ml}$ of blood volume per $\mathrm{kg}$. Therefore although in the WHO Near Miss Audit, the requirement of $\geq 5$ units of blood transfusion is considered to be a severe PPH and a criterion for severe acute maternal morbidity, in a Lankan pregnant woman at term whose body weight is $50-55 \mathrm{~kg}$ even a 1.5 - 2 L blood loss can have serious adverse effects. Therefore it would be prudent to consider only the women who required $<3$ units of blood transfusion as having had a moderate PPH and this is the basis for the sub categorization and analysis of women who had 3-4 units of blood.

Of the 61 cases PPH, the fact that $20(32 \%)$ had $>3$ units of blood transfused, and 21 (34\%) required admission to the ICU is of great concern. Of the ten $(16 \%)$ women who required $>5$ units of blood, the five who required between $7-12$ units and the woman who required 15 units of blood could easily have succumbed to the PPH if the management was sub optimal. Because of the urgency three women had been transfused group specific uncrossmatched blood. The fact that no women were transfused O Negative blood confirms that all the women who required a blood transfusion very urgently had their blood group recorded on the case notes prior to delivery, as it should be.

Although a retained placenta was considered as a criterion for inclusion every case with a retained placenta need not have a clinically significant PPH. Only three $(5 \%)$ of women who had a retained placenta were transfused with at least one unit of blood and therefore were considered to have had a clinically significant PPH.

The rate of PPH in the unit (642 per 100,000 deliveries) is more than 130 times greater than the national case fatality rate of PPH reported in 2008 (4.9 per 100,000 deliveries). This emphasizes the need to carry out audits of this nature. The rate of severe PPH progressively doubled from vaginal delivery to CS to instrumental vaginal delivery and IOL and AOL were the leading risk factor for PPH. This emphasizes the need to properly select women who require IOL, instrumental vaginal delivery and CS, and to anticipate and prevent PPH in these cases and in the event a PPH occurs to detect it early and institute appropriate management.

Trauma (especially vaginal and cervical tears) accounted for $59 \%$ of cases of PPH and Tranexamic acid therapy was carried out in $47.5 \%$ of cases. This observation combined with the markedly high rate of $\mathrm{PPH}$ with instrumental vaginal delivery requires an in depth analysis and appropriate measures should be adopted to address this issue. Although vaginal packing was carried out in 29 cases, in three of them it was probably unnecessary because the underlying cause was considered to be only uterine hypotonia in them.

The fact that a approximately one in three cases of $\mathrm{PPH}$ were detected within 15 minutes and more than half the cases were detected within 30 minutes emphasizes the importance of close monitoring of the mother immediately after delivery. Although a specialist was involved in the management within 30 minutes in $23 \%$ of cases, the fact that in $18 \%$ of cases the specialist was apparently involved in the management of the case only after two hours and in another $23 \%$ the timing of involvement of a specialist was not recorded, is of great concern. Similarly that fact that only $25 \%$ of cases requiring management in the OT were shifted to the OT within 60 minutes and the fact that seven women were shifted to the OT after two hours is also of concern. 
The rates of hysterectomy and bilateral internal iliac artery ligation were relatively high $(21 \%$ and $8 \%$ respectively) compared to B Lynch compression suture (3\%). This too needs an in depth analysis.

The pre transfusion haemoglobin $(\mathrm{Hb})$ being checked in only $65 \%$ of cases is acceptable, because in the presence of a severe acute haemorrhage, a clinical decision is taken and the pre transfusion $\mathrm{Hb}$ is often not checked. However prior to discharge from hospital a patient with a $\mathrm{PPH}$ should have the $\mathrm{Hb}$ and haematocrit (Hct) checked. Prior to discharge from hospital, the $\mathrm{Hb}$ and Hct being not checked in $15 \%$ and $39 \%$ of cases respectively, is of concern.

Recording of timing and details of management in the data collection form was found to be incomplete and sub optimal in up to $31 \%$ of cases with regard to a few variables. When carrying out such an audit it is important to collect and record all the relevant data because missing data may lead to incorrect interpretations and conclusions.

\section{Conclusions}

Morbidity due to $\mathrm{PPH}$ is more than 130 times greater than the proportion of deaths due to PPH. During the period of study there were 23 cases of severe $\mathrm{PPH}$ and these women could have succumbed to the $\mathrm{PPH}$ if not for early and appropriate aggressive management. Proper selection of women is required when embarking on IOL, IVD and CS, to anticipate and prevent $\mathrm{PPH}$ in these cases and in the event a PPH occurs to detect it early and institute appropriate management. An in depth analysis is required and appropriate measures should be adopted to reduce the risk of $\mathrm{PPH}$ due to vaginal and cervical trauma. Women should be closely monitored during the immediate post partum period and in the event a $\mathrm{PPH}$ occurs and if medical management fails, the patient should be shifted to the OT within one hour for appropriate surgical interventions. The specialist concerned should be involved in the management within one hour. The possibility of using appropriate surgical measures to conserve the uterus in cases of severe PPH should be explored. All women who have had a PPH should have the $\mathrm{Hb}$ and Hct levels checked prior to discharge. Recording of timing and details of management of $\mathrm{PPH}$ in the case notes should be improved.

Following this audit, appropriate remedial measures have been adopted in the unit.

\section{References}

1. Coker A, Oliver R. Definitions and Classifications In. BLynch C, Kieth HG, Lalonde AB, Karoshi M (Eds.) A Text
Book of Post Partum Haemorrhage: A comprehensive guide to evaluation, management and surgical interventions. 1st Edn. Sapians Publishing, Duncow, Kirkmahoe, Dumfriesshire, UK 2006, p 11-16.

2. Cameron MJ, Robson SC. Vital Statistics: An overview In: B- Lynch C, Kieth HG, Lalonde AB, Karoshi M (Eds.) A Text Book of Post Partum Haemorrhage: A comprehensive guide to evaluation, management and surgical interventions. 1st Edn. Sapians Publishing, Duncow, Kirkmahoe, Dumfriesshire, UK 2006, p 17-34.

3. Khan KS, Wajdyla D, Say L, Gulmezoglu AM, Van Look PFA. WHO Analysis of causes of maternal death: a systematic review. Lancet 2006; 367: 1066-74.

4. Lalonde A, Daniss BA, Acosta A, Herschderfer K. Post Partum haemorrhage today: ICM/FIGO Initiative 20042006. International Journal of Gynaecology and Obstetrics 2006; 94(3): 243-53.

5. Family Health Bureau, Ministry of Health Care and Nutrition of Sri Lanka. Annual National Maternal Mortality Review 2008. Family Health Bureau, Ministry of Health Care and Nutrition of Sri Lanka, Colombo 2011.

6. Family Health Bureau, Ministry of Health Care and Nutrition of Sri Lanka. Annual Report on Family Health 2008 - 2009. Family Health Bureau, Ministry of Health Care and Nutrition of Sri Lanka, Colombo 2011.

7. Prendiville WJ, Elbuourne D, Mc Donald S. Active versus expectant management in the third stage of labour. Cochrane Data Base of Systematic Reviews 2000. Issue 3. Art. No.: CD000007. DOI: 10.1002/14651858.

8. Carine R. Severe acute maternal morbidity in low income countries. In: Arulkumaran S. Pattinson R (Eds.) Near Miss Audit in Obstetrics. Best Practice and Research. Clinical Obstetrics and Gynaecology 2009; 23: 305-16.

9. Say L, Souza JP, Pattinson RC. Maternal near miss - towards a standard tool for monitoring quality of maternal health care. Best Practice and Research Clinical Obstetrics and Gynaecology 2009; 23: 287-96.

10. Graham WJ. Criterion-based Clinical Audit in Obstetrics: bridging the quality gap? In: Arulkumaran S. Pattinson R (Eds.). Near Miss Audit in Obstetrics. Best Practice and Research. Clinical Obstetrics and Gynaecology 2009; 23: 375-388.

11. Eugene JK, Mlava G, van den Broek N. Using criteria based audit to improve the management of post partum haemorrhage in resource limited countries: A case study of Malawi. Maternal Child Health Journal 2009; 13: 873-8.

12. World Health Organization. WHO Recommendations for the Prevention of Post Partum Haemorrhage. World Health Organization, Geneva 2007.

13. World Health Organization. WHO Guidelines for the Management of Post Partum Haemorrhage and Retained Placenta. World Health Organizatio, Geneva 2009.

14. Royal College of Obstetricians and Gynaecologists. Green Top Guideline No.52. Prevention and Management of Postpartum Haemorrhage. Royal College of Obstetricians and Gynaecologists, London UK 2009. 
15. Scottish Obstetrics Guidelines and Audit Project. The Management of Post Partum Haemorrhage 1998 and Guideline update 2007.available @ www.abdn.ac.uk/ spcerh. accessed on 12 December 2008.

16. Sri Lanka College of Obstetricians and Gynaeclogists. Guideline on Prevention and Management of Postpartum Haemorrhage. Sri Lanka College of Obstetricians and Gynaecologists, Colombo 2009.

17. Department of Making Pregnancy Safer, WHO. Management of Primary Post Partum Haemorrhage. Integrated Management of Pregnancy and Childbirth.
Standards of Maternal and Neonatal Care 4.3. World Health Organization, Geneva 2007.

18. Penny G, Adomson L. Scottish Confidential Audit of Sever Maternal Morbidity. Fourth Annual Report 2006. Scottish Program for Clinical Effectiveness in Reproductive Health Edinburgh UK 2007.

19. British Committee for Standards in Haematology: Working Group: Stainsby D, MacLennan S, Thomas D, Isac J, Hamilton PJ. Guidelines on management of massive blood loss. British Journal of Haematology 2006; 135: 634-41. 